\title{
Not Known if Peripheral Blood Immunophenotyping and Cytochemistry Were Performed
}

National Cancer Institute

\section{Source}

National Cancer Institute. Not Known if Peripheral Blood Immunophenotyping and

Cytochemistry Were Performed. NCI Thesaurus. Code C160464.

An indication that it is not known if immunophenotyping and cytochemistry were

performed on peripheral blood samples during the study. 